\title{
PROPAGANDA EN EL CINE DEL NEW DEAL: LOS PERSONAJES DE JUAN NADIE (FRANK CAPRA, 1941)
}

Valeriano Durán Manso

Universidad de Cádiz

Data recepción 2019-08-09

Data aceptación 2020-04-30

Contacto autor: valeriano.duran@uca.es

ORCID: https://orcid.org/0000-0001-9188-6166

\section{RESUMEN}

Los medios de comunicación desempeñaron un importante papel en la difusión del New Deal durante la década de los 30. La propaganda de sus políticas, vinculada a una clara intención pedagógica y al compromiso con la sociedad para intentar superar la Gran Depresión, tuvo en el cine un oportuno aliado. En este contexto, destacó Frank Capra, uno de los cineastas más populares de estos años y que mejor conectó con el público americano debido a sus películas positivas e idealistas. Con los objetivos de poner en valor la propagación del New Deal en el cine de Hollywood y reflexionar sobre la aportación de Capra, se analizan como persona y como rol -según las teorías de Casetti y Di Chio-, los personajes de Juan Nadie (1941). Los protagonistas encarnan el ideal de sociedad newdealista al funcionar como modelos para los espectadores, mientras que los antagonistas representan el peligro del fascismo.

Palabras clave: propaganda, New Deal, cine clásico, personajes, Frank Capra

\section{ABSTRACT}

The media played an important role in the dissemination of the New Deal during the 1930s. The propagandising of its policies, which was clearly pedagogical in its intent and reflected a commitment to society in an effort to overcome the Great Depression, had a timely ally in the film industry. It was an environment in which Frank Capra stood out. One of the most popular filmmakers of the day, he connected with the American public better than anyone, through his positive and idealistic films. With the aim of highlighting how the New Deal message was spread in Hollywood's films and reflecting on Capra's contribution, this paper analyses the characters of Meet John Doe (1941) as both people and roles, in line with Casetti and Di Chio's theories. These characters embody the ideal of New Dealist society, in that they function as role models for audiences, while the antagonists represent the dangers of fascism.

Keywords: propaganda, New Deal, classic cinema, characters, Frank Capra

\section{Introducción}

Las nefastas consecuencias del Crack de 1929, además de la transición hacia el cine sonoro, marcaron la producción de Hollywood a principios de los años 30, poniendo fin al mito de la prosperity que había caracterizado a los 20. Con este panorama de crisis, las políticas del New Deal (19331939), fomentadas por el presidente Franklin
Delano Roosevelt, no tardaron en ser difundidas a través de los medios de comunicación de masas, sobre todo la prensa y la radio, para recuperar el optimismo de la población y el espíritu americano. En esta labor propagandística -y como estaban haciendo regímenes radicalmente opuestos a la democracia, como el comunista y el fascista-, el cine clásico ocupó un papel esencial, tanto en el 
ámbito documental como en el de ficción, donde se centra este artículo. La respuesta favorable de Hollywood al mensaje de Roosevelt permitió que el cine se pusiera al servicio del New Deal, y especialmente un estudio como Warner Bros. con la producción de películas sociales. Así, se puso de relieve la apuesta de Hollywood por conseguir desde la pantalla "la reeducación de los principios morales de la sociedad" (Mainer 2013, 187); una estrategia que tuvo una rápida expansión en Estados Unidos al ser el cine la industria cultural más popular del momento.

El cineasta más vinculado al espíritu del New Deal fue Frank Capra -quien pudo desarrollar un cine de autor en plena era del sistema de estudios-, pues la cumbre de su éxito y popularidad coincidió con los años de la Depresión y la propagación de las citadas políticas sociales. Su tendencia por el idealismo impregnó los temas y los personajes de sus filmes, implantando lo que denominó Gubern "los cantos apologéticos del American Dream" $(2016,388)$ en el cine de Hollywood, al contribuir al lanzamiento de un mensaje patriótico, positivo y de unión de la sociedad que favorecía la expansión de las iniciativas de Roosevelt a través de la pantalla. Considerado con John Ford y William Wyler uno de "los 'tres grandes' del cine americano de anteguerra" (Gubern 2016, 247), Capra ha sido un director ligado a la propaganda americana, incluso en el cine documental, donde destacó con la célebre serie Why We Fight (1942-1945), filmada para el War Department en la Segunda Guerra Mundial. Además, junto a Ford, aborda en sus relatos "gestas de búsqueda o reconstrucción del hogar perdido a través de tres claves: familia, lucha épica y América como espacio doméstico" (Sánchez-EscaloniIla 2013, 72), transmitiendo la imagen de que el país era el hogar de todos los norteamericanos, sobre todo en tiempos de crisis. En este sentido, se parte de la idea de que el interés pedagógico por fomentar una serie de valores en la sociedad estadounidense conlleva otro propagandístico orquestado desde Hollywood.

Así, se aborda como estudio de caso la película Juan Nadie (Meet John Doe, 1941), donde Capra realiza una apuesta por el compromiso social y alerta del peligro que puede suponer abandonar las pautas del New Deal. Se trata de un filme "sobre el espíritu de la comunidad" (Willis 1998, 42), que lanza este claro mensaje mediante sus protagonistas -interpretados por Barbara Stanwyck y Gary Cooper-, dos representantes del americano medio que creen en los postulados de Roosevelt para construir el espíritu americano. Además, ambos evidencian "la fe de Capra en la persona, en el individuo y de cómo sus actos influye en los suyos, en la comunidad" (Machacuay 2007, 127). De esta manera, el análisis de personajes planteado como persona y como rol pretende demostrar la dicotomía entre los ideales del cineasta -que son newdealistas-, y los de carácter totalitario -que amenazaban desde Europa e iban calando en Estados Unidos-, para generar una conciencia social, pues, como indica Edward Dmytryck, "tenemos que mostrar la maldad para cooperar con la bondad" (Pavés 2019, 148). Esta idea queda plasmada en los antagonistas de Capra, construidos para que el público rechace la perversión que representan y admiren a unos protagonistas defensores del idealismo.

Desde estas consideraciones, el objetivo general de este estudio es poner en valor el papel del cine clásico en la difusión de los valores del New Deal a través de las películas realizadas y protagonizadas por algunos de los directores e intérpretes más relevantes de Hollywood. Para ello, se plantean los siguientes objetivos específicos: observar la difusión de estos ideales en el cine americano y conocer el contexto hollywoodiense de los años 30; reflexionar sobre la aportación narrativa de Capra y la construcción de sus filmes más próximos a los mismos; y analizar a los tres personajes principales de uno de sus títulos esenciales, Juan Nadie, como modelos sociales y de americanismo presentes durante el New Deal.

\section{Marco teórico}

\subsection{El cine del New Deal: evasión y propa- ganda}

El cine clásico de Hollywood experimentó una acusada transformación tras el Crack de 1929, que afectó especialmente al desarrollo de los géneros narrativos, al planteamiento temático y a la construcción de los personajes. A pesar de las graves consecuencias de la crisis, el séptimo arte no fue especialmente perjudicado en 
la taquilla, pues se despertó en los espectadores "una necesidad casi patológica de evasión y de diversión, lo que tuvo como consecuencia que la industria cinematográfica fuese una de las poquísimas del país que no sólo no perdió terreno, sino que ascendió verticalmente en estos años" (Gubern 2016, 234). A esto contribuyeron las iniciativas del presidente republicano Herbert Hoover (1929-1933) de facilitar el acceso al cine a aquellas personas más desfavorecidas mediante el reparto de entradas gratuitas junto con ropa y hasta comida. Aunque Hoover conocía bien el poder del celuloide para entretener a las masas, fue la administración demócrata de Roosevelt (1933-1945) la que mejor explotó las posibilidades políticas e ideológicas del cine, al apostar por "un dispositivo cultural que curaba la crisis 'desde dentro' de la conciencia colectiva de la sociedad, haciendo renacer la esperanza en la capacidad de regeneración del sistema al reforzar la confianza del individuo en su propio afán de mejora" (Mainer 2013, 177). Así, mediante el progresista New Deal, se adoptaron medidas de tipo industrial, relativas a la reforma agraria, de política social, contra el desempleo y de carácter cultural. Estas iniciativas gubernamentales del nuevo presidente se articularon en un triple eje-socioeconómico, ideológico y cultural-, con el fin de reactivar el país y fomentar el espíritu americano entre la población:

El sueño americano y el americanismo eran, evidentemente, proyecciones ideales, construidas sobre bases sólo parcialmente ciertas, pero para los habitantes de los Estados Unidos de los años treinta, y en la estrategia ideológica del gobierno, el recordatorio de la labor de los pioneros y los valores asociados a la frontera: el individualismo, la iniciativa y la tenacidad, pero también el sentido de colectividad, la buena vecindad y la ayuda al prójimo debían actuar como ejemplos ante los difíciles momentos que afrontaban (Girona 2008, p. 53).

En este cometido, los medios de comunicación tuvieron un papel muy relevante. La prensa se había convertido en un fenómeno social americano en los años 20, que se extendió a la década siguiente -especialmente el amarillismo-, en los entornos urbanos. De hecho, fue en esos años de auge económico cuando se produjo "un 'boom' del periodismo y del cine [...]. El público consu- mía películas 'populares' y prensa 'popular' con idéntica voracidad" (Laviana 1996, 159). No obstante, la repercusión masiva de la radio convirtió a este medio en el protagonista para divulgar las informaciones del New Deal, incluso desde el propio gobierno. Debido a su poder de influencia, era el preferido por Roosevelt para propagar las políticas de este programa, como reflejó en sus frecuentes fireside chats (Huici 2017), en los que hablaba a los oyentes de forma clara y familiar con la idea de persuadirles sobre sus novedosas medidas. Junto a la radio, y en lugar de la prensa, este presidente optó también por los informativos cinematográficos para transmitir mensajes que pretendían conocer a la gente e incluso educarla. Por ello, "los medios de comunicación fueron agente esenciales en la gran mediación newdealista, ya fuera racionalizando el aspecto social, transmitiendo a la gente el optimismo pragmático del presidente o actuando como vehículo de información y contacto" (Muscio 1996, 24).

En cuanto a la industria fílmica, y a pesar de las políticas intervencionistas de sus gobiernos, "Hollywood formed a close relationship with the political and cultural programme of Roosevelt in the 1930s and was able to assume a position of cultural leadership" (Smedley 2011, 47). El presidente actuó de manera permisiva con la situación monopolística de Hollywood, donde cinco grandes estudios -Metro Goldwyn Mayer, Warner Bros., Paramount, RKO y Twentieth Century Fox-, dominaban el negocio en detrimento de los pequeños o independientes. Esta actitud se tradujo en una estrategia beneficiosa para ambas partes, pues mientras estas majors "se veían favorecidas al controlar todas las fases de proceso de producción, distribución y proyección de una película sin temor a la competencia", el gobierno y las instituciones eran plasmados en la pantalla "como salvadores del país que había estado a punto de perderse entre las garras de la Depresión y del miedo" (Mainer 2013, 178). Así, la propaganda estatal se instaló en Hollywood, y, en consecuencia, en las tramas de las películas, que empezaron a estar marcadas por una aculturización patriótica y social y por la imposición del happy end. El cine de ficción transmitió eficazmente las bases newdealistas, de modo que se establecieron dos líneas de intervención ideológica en estos años: "la estabilización social y 
la reelaboración del concepto de americanismo" (Muscio 1996, 25). Con ello, se orientaba la capacidad de las películas para generar opinión pública, pues la industria cinematográfica era, junto con la radio, "la máxima instancia creadora de opinión" (Torreiro 1996, p. 43).

En estos años la clase media se convirtió en el principal público del cine americano clásico y se produjeron cambios en las tendencias culturales y de ocio de los espectadores. La crisis fue decisiva en la notable migración del público desde el teatro a las salas de cine debido al bajo coste de las entradas, así que Hollywood experimentó a principios de los años 30 un periodo de gran libertad, que, a nivel temático, permitió el tratamiento de temas como la corrupción, el crimen, la libertad sexual o la crítica a las instituciones públicas. Debido al carácter masivo del cine, la industria no tardó en regular esta cuestión para evitar que el público imitara las controvertidas conductas que aparecían en la pantalla, y, también, para que ésta se convirtiera en un escaparate idílico de la sociedad americana. Así, el periodo conocido como Pre-Code (1930-1934) -en el que los filmes respiraban "una libertad, al fin y al cabo una normalidad, que tardaría décadas en reaparecer" (Freixas y Bassa 2012, 56) -, dio paso a la hegemonía del Código Hays, que se mantuvo hasta 1967:

Su objetivo final es que las películas americanas presenten una sociedad inmaculada, confortable, justa, ponderada, estable, aséptica y tranquilizante, en donde la lacra y el error son sólo pasajeros y accidentales. Una sociedad que insufle a los americanos el orgullo de ser tales y a los extranjeros la envidia y la admiración de su modélico way of life (Gubern 2016, 237).

El código implantó una férrea censura y apostó por una visión "hipócrita y puritana que tendía a ignorar algunas de las realidades más fundamentales de la vida" (Coursodon 1996, 230), lo que influyó también en la construcción maniquea de los personajes. Por ello, en los filmes de este periodo "los sujetos que actúan de un modo positivo ven recompensadas sus acciones al ser premiados, del mismo modo que son castigados los caracteres con un comportamiento voluntariamente dañino" (Pérez Rufí 2009, 93). Además, Dmytryck asegura que "antes de la guerra, los personajes habían sido estereotipos" (Pavés 2019, 137), y así se plasmó en los géneros más desarrollados durante la década. Entre ellos, destacaron la comedia -especialmente la screwball comedy, que inauguró Capra en 1934 con Sucedió una noche (It Happened One Night)-, el musical, el policiaco, el llamado americana, el de aventuras y el melodrama. No obstante, la Depresión favoreció la realización de filmes de marcado carácter social, de cineastas como King Vidor, Mervyn LeRoy, Fritz Lang, John Ford o Capra, quien se convirtió en el "portavoz de la era rooseveltiana" (Gubern 2016, 236) y, a pesar de sus destacadas incursiones en la comedia, ofreció en estos años un corpus fílmico "visiblemente comprometido con estas cuestiones" (Girona 2008, 54).

Algunos rasgos de las películas del New Deal son la apuesta por argumentos de la realidad cotidiana para favorecer la identificación del público con los protagonistas; el optimismo, el valor y la esperanza ante la adversidad; la exaltación de las instituciones gubernamentales; el retorno a los mitos de la América profunda; o "el cultivo de la emotividad" y "la educación en la cultura cívica" (Sánchez Noriega 2018, 340). A este respecto, el talante social del programa entroncaba también con los valores morales y conservadores del Código Hays, que estaba vinculado a organismos de presión como la Legión Católica de la Decencia. Esto evidencia el interés existente por parte del poder político para que el ideario de Roosevelt llegara a amplios sectores de la sociedad americana desde Hollywood.

\subsection{El universo de Frank Capra y sus perso-} najes idealistas

Capra es un cineasta de la contemporaneidad, pues, salvo las excepciones de La amargura del general Yen (The Bitter Tea of General Yen, 1932) y Horizontes perdidos (Lost Horizon, 1937), sus filmes transcurren en Estados Unidos y hablan de los problemas del americano medio. Esta tendencia por la actualidad podría responder a motivos económicos -al evitar las costosas producciones históricas-, dentro de un estudio perteneciente a las minors como Columbia, pero le permitía realizar filmes enmarcados en el drama social del momento, especialmente durante los años 
más duros de la crisis, como La locura del dólar (American Madness 1932), donde critica y, posteriormente, confía en el sistema bancario. Además, también posibilitó que el cineasta rodara otros de carácter ideológico a finales de los 30 y a principios de la década siguiente, precisamente cuando el auge del fascismo en Europa empezó a convertirse en una amenaza para Estados Unidos, y, por extensión, para los avances sociales del New Deal. Esto refleja que "del mismo modo que reivindicaba una América casi utópica, con una historia mitificada, Capra también defiende una democracia idealizada" (Pelaz López 2010, 97). Determinado por la difícil coyuntura socioeconómica de la Depresión, el director plasmó la base ideológica de toda su filmografía en sus primeros filmes, que, como indica Girona,

ofrecieron, ante la nueva América de la abundancia, del hedonismo y del afán materialista que retrataban, un discurso que privilegiaba valores intangibles como el amor, la amistad, el afecto $y_{\text {, }}$ junto con ellos, una, a veces difusa, aunque otras muy explícita, nostalgia por el pasado, por aquellas formas culturales y sociales que estaban condenadas a desaparecer ante el cambio que experimentaba el país $(2008,49-50)$.

En esta tarea ocupó un relevante lugar Robert Riskin, uno de los guionistas y principales colaboradores del director. Ambos desarrollaron un "optimismo crítico" que pretendía exhibir a través de sus filmes "la inquebrantable salud del sistema democrático americano" (Gubern 2016, 235). Así, este espíritu positivo e ideológico quedaba ligado a la fórmula planteada por el Gobierno de Roosevelt para paliar las adversas consecuencias de la Depresión, es decir, el New Deal, y fue decisivo en el universo narrativo de Capra, como se percibe en el talante idealista de sus películas de la segunda mitad de los 30 . A este respecto, se puede afirmar que el tema central de la obra del cineasta es la preocupación personal y relativa a su comunidad del americano medio; el mismo que sufría de forma más directa los efectos del crack bursátil y necesitaba ver en el cine que un mundo mejor podía ser posible. Otras de sus constantes temáticas son el individualismo, pero, a la vez, el compromiso con el entorno, o el análisis de la realidad, además de la bondad, el sacrificio, la derrota, la esperanza, la renuncia o la ilusión. El pasado suele ocupar también un lugar esencial en sus filmes, pero no aparece como un conjunto de tradiciones o de anécdotas, sino como "una fuerza social por recuperar" (Muscio 1996, 31). A pesar del difícil panorama de crisis, este planteamiento indica que Capra apuesta por la unión de las personas al ofrecer "soluciones personales, humanas, basadas en su inconmovible fe religiosa" (Pelaz López 2010, p. 108).

Así, los protagonistas masculinos de los filmes de su segunda etapa, El secreto de vivir (Mr. Deeds Goes to Town, 1936), Caballero sin espada (Mr. Smith Goes to Washington, 1939), la propia Juan Nadie o ;Qué bello es vivir! (It's a Wonderful Life, 1946), "quedan destrozados por sentimientos de autocompasión, desprecio de sí mismo, rechazo directo o indirecto de sus ideales o cualquier variante del fracaso final a que se ven abocados" (Willis 1988, 14). Esto muestra que los héroes de Capra no son seres solitarios o fuertes -como correspondería al ideal clásico de héroe-, sino "vulnerables, relacionales, capaces de amar y... enamorados" (Peris Cancio y Sanmartin Esplugues 2017, 151). En la representación de este rol durante el New Deal, el star system desempeñó un lugar esencial, pues la elección del intérprete tenía una notable influencia en el público y era preciso que el americano medio viera en este ser de ficción un modelo a seguir. Por este motivo, Gary Cooper y James Stewart -protagonistas de las cuatro películas citadas-, Henry Fonda o Spencer Tracy, fueron los actores que más veces lo encarnaron en estos años. Esta interrelación entre actor y personaje pone de relieve que "el cine clásico saca partido de las connotaciones previas de la estrella y, al mismo tiempo, las enmascara, presentando a la estrella como personaje" (Bordwell, Staiger y Thompson 1997, 16), como sucede con Cooper en Juan Nadie.

Mientras que el héroe de Capra encarna valores como la honradez, posee un espíritu positivo y una arraigada moral, muestra un talante ingenuo, cuenta con la admiración de su entorno y exhibe una notable preocupación por la recuperación de otros personajes o del bien común, las heroínas presentan unos rasgos que los complementan y las convierten en unos personajes esenciales para el desarrollo de las tramas. Las protagonistas del cineasta suelen mostrar un carácter intrépido, 
una actitud decidida, una fuerte personalidad, un espíritu cosmopolita, y, además, aparecen tanto en entornos domésticos como laborales, donde ejercen su profesión de forma entregada y con un considerable éxito. En este sentido, debido a la Depresión, el cine clásico promovió en los años 30 la figura de la mujer -especialmente en los roles de madre y esposa-, como el sostén moral de la familia, pero también contribuyó "a la consolidación de un nuevo modelo de mujer, alejada de los roles tradicionales, cuyas actitudes influirán en una progresiva e irreversible transformación del ámbito familiar" (Lanuza Avello 2010). En línea con la working girl (Guiralt Gomar 2008) se enmarcan algunas protagonistas de los filmes de la segunda etapa de Capra, quienes destacan, además, por su talante resolutivo. Estos perfiles, masculinos y femeninos, intentaron reflejar al espectador medio estadounidense, y, por otra parte, indicaron que "the greatest exponent of Hollywood's new idealism was perhaps Frank Capra" (Smedley 2011, 72).

Al hilo de la omnipresencia y el auge de los medios de comunicación de masas en la sociedad americana, Capra mostró especial interés por abordar el mundo del periodismo y por construir personajes periodistas, como expresó en El poder de una lágrima (The Power of the Press, 1928), Sucedió una noche y Juan Nadie, donde Douglas Fairbanks Jr., Clark Gable y Barbara Stanwyck, respectivamente, interpretaron a protagonistas reporteros y columnistas. En ellas, el cineasta apostó por entornos urbanos como espacios dinámicos de oportunidades, prosperidad y modernidad, radiografiando la vida americana de la época y mostrando "una vívida imagen de Estados Unidos" (Girona 2008, 47). Además, planteó otro de los aspectos comunicacionales que más le preocupaban, la dimensión política de los medios y su capacidad para poder influir en los ciudadanos, alertando "a los espectadores de los peligros que entrañan las grandes corporaciones y los manipuladores mediáticos" (García de Lucas, Rodríguez Merchán y Sales Heredia 2006, 49). Sin duda, la personalidad que imprimió en sus filmes, su libertad creativa, y, además, la gran popularidad que experimentó especialmente durante los años 30, permitió a Capra imponerse como uno de los escasos cineastas autores que admitieron el rígido sistema de estudios, en este caso Co- lumbia. El contrato que firmó en 1935 con este estudio fue uno de los más favorables para un cineasta que se habían negociado en Hollywood hasta la fecha. Concretamente, "it provided for him to produce and direct four pictures over a two-year period and guaranteed him a salary of $\$ 100,000$ per picture and 25 percent of the net profits, with each picture separately accounted" (McBride 2011, 329).

\subsection{Juan Nadie (1941): contexto, temas y} personajes

Esta película es la primera que produjo el cineasta con el sello Frank Capra Productions, tras dejar Columbia en 1939, y pertenece a la segunda y más fructífera etapa de su filmografía. En ella apuesta por mostrar la corrupción de la sociedad y ofrecer la propagación de los valores del New Deal como una solución ideológica posible. Además, ante el contexto mundial del momento, supone una denuncia "explícita de los peligros del fascismo" (Pelaz López 2010, 101), que supondría la desaparición de valores ligados a Estados Unidos como la libertad y la democracia. La trama contó con el guion de Riskin -productor del filme junto a Capra-, y se basaba en el relato $A$ Reputation, de los escritores y guionistas Richard Connell y Robert Pressnell, que se había publicado en prensa en 1922 y adaptado al teatro en 1939 bajo el título de The life and the death of John Doe. Aunque contaba con el apoyo del público, el director anhelaba el definitivo respaldo de la crítica, como expresa en sus memorias:

Mi primera aventura cinematográfica completamente independiente, fue orientada a conseguir la aclamación de la crítica. Los éxitos del brazo fuerte de Hitler contra la democracia estaban creando escuela. En toda Norteamérica surgían pequeños führers que proclamaban que la libertad era algo débil, estéril, pasado. iLa 'nueva ola' era el Poder de la Sangre! Destruye a los débiles, los judíos, los negros; destruye el cristianismo y su anticuado mandamiento de 'ama a tu semejante'. ¡Arriba la Herrenvolk! Riskin y yo asombraríamos a los críticos con realidades contemporáneas: el feo rostro del odio: el poder de los fanáticos de uniforme con camisas rojas, blancas y azules; la agonía de la desilusión, y las oscuras pasiones salvajes de las multitudes (Capra 2000, 349). 
En cuanto a los temas que aborda, la película realiza una crítica a la prensa sin escrúpulos que se impone para hacer negocio más que para informar sobre la problemática social. El ejemplo más claro es la destrucción del rótulo grabado en piedra de la entrada del edificio donde está el periódico, y que indica 'The Bulletin: la prensa libre garantiza la libertad de las personas', para colocar otro que reza 'The New Bulletin: un periódico moderno para una nueva era'. Este cambio de eslogan determina el desarrollo de la historia, pues la apuesta por esta modernidad en detrimento de la libertad supone un reajuste de la plantilla -y despidos de trabajadores-, y un giro bastante radical en la línea editorial. Cuando un periódico realiza cambios de este tipo, "los hace para adecuarse a los tiempos, satisfacer a sus lectores y, por supuesto, para vender más. Lo cual es lícito", pero "lo peor es que muchos lo hacen para ser más 'populares' $y$, sin darse cuenta, más amarillos" (Laviana 1996, 173). Así, el filme destaca la hegemonía que tenía la prensa en Estados Unidos a principios de la década de los 40 -y el auge producido durante el New Deal-, además de su lado más oscuro para potenciar "el formidable papel de los mass-media por influir y manipular en la gente mediante métodos ilegítimos y fraudulentos" (Aguilera y Grau 2015, 172). La creación de un personaje como Juan Nadie aumenta las ventas del amarillista The New Bulletin, pues los lectores se identifican con él, de modo que se convierte en un fenómeno social, e incluso político.

Capra presenta los temas sobre la situación social de Estados Unidos en estos años en la carta que supuestamente envía John al periódico pero que escribe Ann en la que iba a ser su última columna. Aquí destaca la incapacidad de los políticos para responder a los ciudadanos, el paro o la corrupción, pero teniendo en cuenta que en el cine clásico la pérdida del empleo en los protagonistas supone "uno de los conflictos principales de la trama que sus héroes habrán de resolver", se plantea "una temática de conflicto social" (Pérez Rufí 2009, 170). También aborda aspectos como el idealismo, el populismo, la manipulación de las masas, el sensacionalismo y el suicidio, que es expuesto "como reclamo y como redención" (Willis 1988, 38). A este respecto, resulta oportuno indicar que el suicidio es un tema recurrente en la cinematografía de Capra, estando presente en varios de los protagonistas de sus filmes:

The temptation to suicide is a major theme of Capra's work. The heroes two of his most personal (and least commercially successful) films before Meet John Doe -The Way of the Strong and The Bitter Tea of General Yen- actually do commit suicide. Failed suicide attempts figure im several other Capra films, and almost every Capra film takes its central character on violent mood swings between elation and despair before reaching fragile happy ending (McBride 2011, 434).

Posteriormente, aparecería también en Qué bello es vivir, así que varios de los filmes que el director realizó desde el periodo mudo hasta la Segunda Guerra Mundial, pasando por el New Deal, tuvieron personajes principales marcados por el intento de suicidio. A pesar de su riqueza temática, su potente apertura y un "desarrollo que ascendía de forma inexorable hasta un clímax espectacular", ni Capra ni Riskin encontraban un buen final para la historia: "es sorprendente, pero cierto; Juan Nadie corría el peligro de no convertirse en un filme clásico porque ¡no podíamos terminarlo!" (Capra 2000, 353-354). Al final, optaron por un desenlace esperanzador, pues enfrentarse a temas tan críticos permitía intensificar la propaganda del New Deal, el espíritu americano, la fraternidad y la unidad.

En lo que respecta a los personajes, el título original, Meet John Doe, conlleva "una invitación a conocer al tipo anónimo y representativo de los valores de las reglas doctrinales del cine de Capra -progresistas, si bien al mismo tiempo fuertemente arraigadas a la moralidad cristiana" (Aguilera y Grau 2015, 168)-. Se trata de un ser de ficción que está próximo al ciudadano medio y que actúa como su portavoz contra el poder de una minoría privilegiada que oprime a la sociedad. John pertenece al típico héroe americano idealista y honesto de Capra, capaz de convertirse en un líder carismático, calar en la sociedad e influir en las masas. Este prototipo de héroe refleja el culto a la personalidad que el cineasta desarrolló en sus películas de estos años, evidenciando "que no solo una persona concreta puede significar un cambio, sino que sin tales individuos estaríamos todos perdidos" (Gallagher 1996, 350). Por su parte, Ann se encuentra en 
la línea de los personajes que encarnaba Barbara Stanwyck, quien combinaba "la cualidad impetuosa y el sex-appeal con la integridad propia de una working class heroine", una ecuación que atendía a "los elementos de radiografía social" (Aguilera y Grau 2015, 30). Junto con Katharine Hepburn, Bette Davis y Joan Crawford -y a pesar de los aspectos que las diferenciaban-, reflejó la imagen de la mujer trabajadora que se había incorporado masivamente al mercado laboral americano y se enfrentaba a la Depresión, y uno de los exponentes hollywoodienses de la mujer moderna.

Para potenciar las fuerzas del bien, las del mal aparecen vinculadas a la corrupción y al auge inminente del fascismo en la sociedad americana víctima de la crisis, como había sucedido en Italia y en Alemania después de la Primera Guerra Mundial. Esto queda plasmado en D. B. Norton, un personaje que mueve los hilos desde su periódico para despertar necesidades en la ciudadanía y una fuerte alarma social con fines políticos. Así, se refleja que el magnate es "el ciudadano que vende opinión" (Laviana 1996, 19), lo que implica manipulación mediática. Estos tres personajes denotan que a pesar del espíritu positivo que Capra imprimió en Juan Nadie, su trasfondo es triste y amargo; una mezcla que le otorgó el reconocimiento de público y de crítica, como indica su Oscar al Mejor Argumento Original.

\section{Metodología}

Esta investigación es de naturaleza cualitativodescriptiva, como se refleja en la metodología empleada. En primer lugar, se ha procedido a una revisión bibliográfica, y posterior lectura, de publicaciones de autores e investigadores relevantes sobre la historia del cine en Estados Unidos, el contexto de la Gran Depresión y del New Deal, el cine realizado durante este periodo, la imposición del Código Hays y los géneros cinematográficos, como Sánchez Noriega, Huici, Gubern, Mainer, Sciomopoulos, Freixas y Bassa, Smedley, Echart, Bordwell, Staiger y Thompson, Coursodon, Muscio y Torreiro. Asimismo, se han consultado publicaciones relativas a la representación fílmica del ámbito periodístico de Estados Unidos durante las décadas de los 30 y principios de la de los 40, de autores como Mera Fernández, García de Lucas,
Rodríguez Merchán y Sales Heredia o Laviana. Por otra parte, también se ha considerado oportuno abordar la perspectiva de género en los seres de ficción de este periodo de la historia del cine, para, concretamente, poder abordar la construcción de los personajes femeninos y los roles que ejercían en los filmes de esta época. Para ello, se ha recurrido a las investigaciones de Lanuza Avello, Guiralt Gomar o Guarinos.

En segundo lugar, se han revisado libros y artículos sobre el director de Juan Nadie, Frank Capra, de autores expertos en su trayectoria cinematográfica, como Peris Cancio y Sanmartín Esplugues, Antuñano, McBride, Pelaz López, Girona, Machacuay, Gallagher y Willis. Del mismo modo, se han consultado las memorias del cineasta y un estudio de uno de los directores contemporáneos a él, Edward Dmytryck, quien reflexiona sobre su universo narrativo en el contexto del Hollywood clásico. Para conocer las aportaciones de la pareja protagonista del filme, Gary Cooper y Barbara Stanwyck, y la construcción de sus personajes, se ha recurrido a las biografías realizadas, respectivamente, por Meyers y Aguilera y Grau. En este sentido, han resultado pertinentes las aportaciones sobre el análisis del personaje audiovisual de Casetti y Di Chio o Chatman para estructurar la plantilla que se aplica a los personajes que se estudian. En tercer lugar, se ha procedido al visionado de la citada película, protagonizada por los tres seres de ficción que se abordan: Ann, John y Norton. En cuanto al resultado de los personajes, se debe señalar que el rostro, el físico, la voz y, en definitiva, la interpretación de los actores que los encarnan -Stanwyck, Cooper y Edward Arnold, en este orden-, están estrechamente ensamblados con su composición cinematográfica. Asimismo, también se ha reflexionado sobre la dimensión educativa de la película.

A continuación, se ha aplicado la plantilla de análisis de personajes realizada en 2009 por el Grupo de Investigación en Análisis de Medios, Imágenes y Relatos Audiovisuales (AdMIRA), de la Universidad de Sevilla, basada en las teorías de Francesco Casetti y Federico Di Chio. Se trata de una herramienta cualitativa que es heredera de las aportaciones de destacados narratólogos, como Chatman, Greimas o Propp; fundamentales 


\begin{tabular}{|c|c|c|c|}
\hline & Ann Mitchell & Long John Willoughby & D. B. Norton \\
\hline Iconografía & & & \\
\hline Edad & & & \\
\hline Apariencia física & & & \\
\hline Vestimenta & & & \\
\hline Habla & & & \\
\hline Transformación & & & \\
\hline Psicología & & & \\
\hline Carácter & & & \\
\hline Relación & & & \\
\hline Pensamiento & & & \\
\hline Sentimientos & & & \\
\hline Evolución & & & \\
\hline Sociología & & & \\
\hline $\begin{array}{l}\text { Nivel social-eco- } \\
\text { nómico }\end{array}$ & & & \\
\hline Nivel cultural & & & \\
\hline Sexualidad & & & \\
\hline Orientación & & & \\
\hline Rol & & & \\
\hline $\begin{array}{l}\text { Papel que desem- } \\
\text { peñan }\end{array}$ & & & \\
\hline Motivaciones & & & \\
\hline Acciones & & & \\
\hline
\end{tabular}

Gráfico 1: Ficha de análisis de personajes como persona y como rol

Fuente: Elaboración propia a partir de la plantilla de análisis del Grupo AdMIRA

en las investigaciones sobre narrativa audiovisual. Esta plantilla, que atiende a aspectos relativos a la iconografía, la psicología, la sociología y la sexualidad, y a otros sobre los roles, permite conocer la apariencia, el habla, el carácter, las relaciones con el entorno, el pensamiento, los sentimientos, la evolución, el nivel socioeconómico y cultural, y la orientación sexual, así como o las motivacio- nes y las acciones de los seres de ficción. A este respecto, se considera que la motivación favorece la acción, así que al clasificar a los personajes en función del rol que ejercen resulta "necesario observar los factores relacionados con la vida personal junto a la relación del protagonista con la acción y el sentido de su actuación" (Pérez Rufí 2009, 269). Esto constata que el análisis como 
persona y como rol están interrelacionados, pues con ellos se pretende apostar por la construcción del personaje como un ser procedente de la vida real, con las mismas inquietudes, problemas y aspiraciones del espectador, para facilitar el proceso de identificación.

\section{Análisis de personajes}

\subsection{Ann Mitchell: una periodista audaz}

La protagonista trabaja como columnista en el periódico The Bulletin, y, después, en The New Bulletin. Ann es una joven e intrépida periodista que mantiene a su familia tras la pérdida de su padre y que posee un firme compromiso social que entronca con el New Deal. Ella encarna un modelo de mujer trabajadora que se siente realizada profesionalmente, pero que tiene que reinventarse para sobrevivir en un ambiente hostil derivado de la Depresión.

Iconografía. Ann tiene unos 25 años, es rubia y destaca por su amplia sonrisa, su mirada expresiva, su estilizada figura y un elegante caminar. Ella suele llevar una vestimenta muy sencilla y modesta en la que destacan los sombreros, y que es acorde a su edad, pero, sobre todo, a sus posibilidades económicas. En cuanto a su forma de hablar, tiene un discurso claro y persuasivo que acompaña con un tono de voz directo que transmite una gran seguridad. Por ello, nunca da rodeos para comunicar algo. La principal transformación iconográfica que sufre se produce en la parte final y se evidencia en el elegante vestuario que porta para cenar con D. B. Norton, y en el cercano y cómplice discurso que emplea con el protagonista.

Psicología. Ann tiene un carácter afable y un comportamiento audaz y enérgico que le permite ser readmitida en el diario gracias a la invención de Juan Nadie, un ciudadano que envía una carta a la redacción para expresar que se siente defraudado por el sistema, está cansado de la corrupción y lleva años en el paro, por lo que amenaza con suicidarse desde el ayuntamiento la noche del 25 de diciembre. Se trata de un personaje anónimo "que en realidad comparte su misma realidad o la de cualquiera de los otros compañeros despedidos por el nuevo director del periódico" (Aguilera y Grau 2015, 172). Aunque ella no esperaba la repercusión que su personaje y la columna que escribe provocan en la sociedad americana, rápidamente se siente identificada con el sufrimiento de éste, pues, en definitiva, es el suyo propio. En cuanto a sus relaciones con los demás, vive con su madre viuda y con sus dos hermanas adolescentes, con quienes se lleva bien. La persona de su familia a quien más admira es su difunto padre, que era autor de un idealista diario que escribió hasta poco antes de morir. Sus páginas son las que la inspiran para redactar los discursos que pronunciará John por todo el país. Con él establece una relación casi maternal porque le infunden ternura su frágil situación y la ingenuidad de su carácter. Además, desarrolla una especie de veneración por él y por los ideales que representa -aunque ella es quien los plantea-, así que ve en John la personificación de los valores de su progenitor. El creciente interés que manifiesta por el joven no tarda en propiciar un vínculo amoroso. En el ámbito profesional, inicia una relación cordial con Norton cuando entra en su círculo de confianza, pues al principio no sospecha de sus intenciones.

El pensamiento de Ann es muy práctico, y esto le permite encontrar soluciones efectivas a los problemas, enfrentarse a ellos y ganarse el respeto de sus compañeros. No obstante, también es emocional, como refleja cuando habla de su padre o con el protagonista, y está arraigado a unas profundas convicciones morales próximas al New Deal y a la defensa de la democracia. Aunque por su implicación en la manipulación de la sociedad pertenecería al nutrido grupo de "periodistas indeseables" (Mera Fernández 2008, 508) que ha dado el cine, lo cierto es que es una chica honesta. Así lo expresa al confesar al editor del diario que se ha inventado a Juan y que la carta no existe. Esto es extensible a los sentimientos nobles que profesa a su familia. En cuanto a su vida amorosa, las responsabilidades del trabajo la tienen tan absorbida que no desarrolla sus verdaderos sentimientos por John hasta que transmite el discurso radiofónico. Ella experimenta una notable evolución psicológica al abandonar las aspiraciones económicas que le permitían conservar su empleo, para luchar activamente por el idealismo que encarna John. El punto álgido se produce cuando toma conciencia del peligro del 
experimento social que ha fomentado y de los intereses reales de Norton, así que decide huir del magnate y seguir en la lucha junto al protagonista, a quien termina confesando su amor.

Sociología. Ann pertenece a la clase media trabajadora, aunque la decoración y la estructura de su casa denotan que antes de la crisis gozó de un estatus superior. En el ámbito social, se percibe que controla perfectamente el mundo en el que se mueve -tanto en las altas esferas como en la redacción del periódico, o incluso en la calle-, y, por ello, sabe elegir a la persona que va a encarnar a Juan Nadie. Asimismo, posee un nivel cultural alto que es propio de su labor profesional, de sus inquietudes intelectuales y de su bagaje vital.

Sexualidad. Ann es heterosexual y no tiene novio. Finalmente, cuando John va a suicidarse, consigue expresarle sus deseos, sentimientos y planes de futuro.

En cuanto al análisis del personaje como rol, la protagonista desempeña los de working class heroine y chica buena. En el primer caso, motivada por mantener su puesto de trabajo, se inventa un personaje que le permite ser readmitida en el periódico, ganar dinero -que, como confiesa, es su principal objetivo-, y aumentar los lectores. Además, convencida de la causa de John, consigue salvarlo del suicidio y del plan fascista de Norton. El segundo rol lo ejerce en el ámbito personal, pues, motivada por el amor que siente por el protagonista, decide protegerlo para emprender juntos una nueva vida.

\subsection{Long John Willoughby: un héroe idealista}

El protagonista es un antiguo jugador de beisbol que dejó este deporte tras lesionarse el codo y ahora está en la indigencia. John intenta sobrevivir sin trabajo y sin un techo donde dormir, pero, a pesar de ello, no necesita mucho para ser feliz. Él representa a las numerosas víctimas anónimas de la Depresión, y esto lo convierte en el modelo idóneo para encarnar a Juan Nadie en la campaña que inicia The New Bulletin.

Iconografía. John tiene poco más de 30 años, es alto y destaca por su sonrisa franca, sus ojos azules y una imagen cercana. Aunque es atractivo, posee una vestimenta casi harapienta que evidencia la precaria situación económica que atraviesa; de hecho, aparece en el diario con la ropa sucia y el pantalón roto. En cuanto a su forma de hablar, tiene carisma y una gran capacidad de oratoria y de convocatoria, como se percibe en su primer discurso radiofónico, aunque al principio muestra un tono tímido. La principal transformación que sufre se percibe en el elegante vestuario que porta tras aceptar dar vida a Juan Nadie, pues el periódico le da una considerable cantidad de dinero. Asimismo, sus palabras se tornan más idealistas.

Psicología. John tiene un carácter sensible, que se advierte en el comportamiento tan honesto, humanitario y razonable que exhibe, especialmente cuando habla de los más desfavorecidos de la Depresión, es decir 'los Juan Nadie' a los que representa con fidelidad e intenta dar voz. Él encarna valores como la integridad, la justicia y la sinceridad en un panorama de crisis, así que se convierte en el modelo perfecto que buscan desde The New Bulletin para personificar al personaje. Además, al ser un ex jugador de beisbol profesional entronca con el espíritu americano y adquiere mayor credibilidad ante los ciudadanos de las clases populares. John acepta el reto de convertirse en Juan Nadie porque desea operarse del codo para poder volver a jugar al beisbol y, también, porque necesita dinero, pues no tiene ni para comer. Sin embargo, los motivos económicos dejan rápido de interesarle. En lo relativo a sus relaciones, John comparte el espíritu solitario y la vida social escasa de los héroes clásicos, y, por ello, solo tiene un amigo en quien confiar, el Coronel -encarnado por Walter Brennan-, un vagabundo que lo conoce muy bien y actúa como su conciencia. Asimismo, con Ann inicia un vínculo personal que se vuelve cada vez más íntimo, pues admira su valor como mujer y su profesionalidad, de modo que puede afirmarse que representa un nuevo modelo de masculinidad para la época. Por su parte, apenas tiene relación con Norton, aunque se enfrenta a él cuando descubre que quiere utilizarlo para sus intereses políticos fascistas.

El pensamiento de John está marcado por unas fuertes convicciones idealistas que están muy ligadas a los valores demócratas del New Deal y al americanismo como forma de unión de los ciudadanos para hacer una sociedad más justa. No obstante, presenta cierta ingenuidad, como 
revela al descubrir que tiene numerosos clubes compuestos por miles de seguidores de todo el país que lo consideran un faro para guiarles. La secuencia de la convención con estos clubes en un estadio de Chicago es la que recoge con mayor precisión sus ideas, pues todos los asistentes, bajo la lluvia, anhelan con esperanza escucharlo. Esta transparencia es común al ámbito de los sentimientos, donde destaca por su nobleza, su capacidad de entrega, y, en la parte final, su amor hacia Ann. La evolución que experimenta el protagonista tiene un origen social, pues parte de una condición anónima y se convierte en un héroe nacional que abandera una causa de manifiesto calado idealista. Aunque va percibiendo el peligro del plan en el que está involucrado, su clímax se produce cuando Norton lo traiciona boicoteando la convención. Esto revela que "Capra alienta al principio las ilusiones de su héroe para después destrozarle" (Willis 1988, 44), una pauta común en varios de sus filmes. La derrota lo lleva al suicidio, pero, finalmente, Ann lo convence de que debe seguir defendiendo su lucha.

Sociología. John procede de un entorno socioeconómico muy deprimido, pues, prácticamente, vive en la calle debido a la Depresión y suele viajar como polizón en los trenes de mercancías junto al Coronel. Esta situación contrasta con sus habilidades sociales, pues sobresale por su capacidad para entender los problemas de los ciudadanos, su oratoria y su don de gentes. Por otra parte, su nivel cultural bajo favorece que sea fácilmente manipulable.

Sexualidad. El protagonista es heterosexual y posee una visión romántica de la pareja, pero este aspecto solo se muestra en el desenlace cuando Ann se declara.

En cuanto al análisis del personaje como rol, desempeña el de héroe idealista. A pesar de que se convierte en Juan Nadie alentado por curar su codo, John muestra una firme convicción por ayudar a los desfavorecidos. Así, motivado por ofrecerles ánimo y confianza en plena crisis, encarna al personaje y no desea abandonarlos el día de Navidad, como estipula su contrato. Por ello, convencido de escapar de la estrategia de Norton, responde al ruego de Ann de no suicidarse para dar voz a los más débiles que siguen creyendo en él.

\subsection{B. Norton: un magnate totalitario}

El antagonista es un magnate del petróleo que adquiere The Bulletin para convertirlo en The New Bulletin. Norton posee un excelente olfato para los negocios y unas aspiraciones políticas ligadas al fascismo, y opuestas al New Deal. Él encarna un modelo de empresario hábil pero implacable que no duda en recurrir a la manipulación para lograr sus propósitos.

Iconografía. Este personaje supera los 50 años, posee una oronda figura y su rostro destaca por un gesto serio y una mirada dura que se percibe a través de sus pequeñas lentes. Debido a esta apariencia física parece mayor para su edad, y en esto influye el sobrio vestuario basado en trajes oscuros y de rayas que suele llevar. En cuanto a su forma de hablar, posee un discurso claro pero parco en palabras que acompaña con un tono firme e hiriente. Su principal transformación se advierte en el esmoquin que porta en la cena donde celebra con directivos de medios de comunicación, y demás personalidades, la carrera política que va a iniciar manejando a Juan Nadie. Asimismo, su habla se torna más sosegada al final.

Psicología. D. B. Norton tiene un carácter dominante que se evidencia en la actitud decidida, prepotente y manipuladora que ejerce en el ámbito mediático y político. Por ello, al conocer el impacto de Juan Nadie en las clases populares decide explotarlo para su beneficio. Así, en él se sintetizan, "en una significativa simbiosis, los magnates a los que Roosevelt criticó durante los años más duros de la Depresión y esos otros personajes, más o menos públicos, que [...] abrazaban la ideología nazi y sus estrategias políticas" (Girona 2008, 275). En cuanto a la forma de relacionarse, entabla con Ann un vínculo profesional para llevarla a su terreno, pues le interesa contar con una periodista que está comprometida con la causa de Juan Nadie y sabe escribirle los discursos. Con John no tiene una relación cercana y tampoco suelen hablar con frecuencia. Sin embargo, cuando éste se niega a su chantaje, Norton despliega su despotismo para aniquilarlo. Con quienes sí mantiene una relación estrecha son su sobrino -y heredero de su imperio-, y el cuerpo de matones que tiene a su servicio. 
Pensamiento. Este personaje es muy inteligente y posee un pensamiento práctico, empresarial y estratega. El éxito de Juan Nadie entre las numerosas víctimas de la Depresión le permite vislumbrar que podría obtener millones de votos con esta nueva corriente popular. Por ello, planifica que John anuncie ante sus seguidores la creación de un tercer partido, una alternativa al Demócrata y al Republicano "dedicado a todos los Juan Nadie del país, lo que equivale al noventa por ciento de los votantes" (Laviana 1996, 174), con el que Norton se postularía como presidente de Estados Unidos. Esta ambición se extiende al ámbito de los sentimientos, pues es frío y sólo parece algo afectuoso con aquellos de los que puede sacar beneficio, como Ann. El magnate experimenta una considerable evolución tras el rechazo de John, pues decide ejercer su posición de superioridad y exhibir todo su poder. Por este motivo, lo desprestigia en la convención ante los clubes llamándolo impostor y recurre a sus motociclistas paramilitares para agitar a las masas contra él, consiguiendo finalmente este cruel propósito.

Sociología. Norton posee un nivel socioeconómico alto debido a sus múltiples negocios y un nivel cultural medio vinculado a su ideología próxima al fascismo que se estaba expandiendo desde Europa. Este estatus le permite desarrollar un aparato político basado en el control de los medios de comunicación, la instrumentalización de un líder, la articulación de un discurso próximo al ciudadano, la creación de estructuras paramilitares de agitación, y la propuesta de un gobierno autoritario "que garantice la seguridad y el orden" (Girona 2008, 278).

Sexualidad. Este personaje es heterosexual, pero se desconoce su estado civil, así como sus relaciones amorosas o sexuales. Este aspecto no aparece desarrollado.

En cuanto al análisis del personaje como rol, ejerce el de villano. Al principio, motivado por aumentar los beneficios del periódico, apoya la iniciativa de Ann, pero el aparato propagandístico que erige en torno a John le permite proyectar una carrera política fascista. Así, motivado por llegar a la Casa Blanca, planifica la explotación de éste para que sus adeptos -perjudicados por la crisis-, lo voten y lo conviertan en el nuevo presidente.

\section{Conclusiones}

Frank Capra es uno de los cineastas más representativos del cine clásico y del New Deal. Su obra cinematográfica, especialmente la de su segunda etapa, constituye el espejo emocional de una época muy concreta de la historia reciente de Estados Unidos, pues, además, muestra un especial interés por reflejar los problemas e inquietudes del ciudadano americano medio. La evolución que experimentó su filmografía desde los primeros años 30 hasta el final de la Segunda Guerra Mundial, responde también al diferente modo en que el republicano Hoover y el demócrata Roosevelt gestionaron la Depresión. Así, el talante optimista del segundo se plasmó en sus filmes rodados entre 1934 y 1946, y contribuyó a animar y a dar esperanza a una sociedad que intentaba evadirse de la crisis a través de la gran pantalla. Durante el New Deal las películas no solo se ofrecían como consumo sino también como servicio, con la intención de ofrecer diversión y educación. Esto evidencia la eficacia del cine para transmitir unos valores sociales determinados desde el propio gobierno, y, además, "como agente difusor de ideologías" (Mainer 2013, 171). Asimismo, la segunda etapa de Capra está enmarcada en un periodo caracterizado por el interés de Roosevelt por transmitir los valores newdealistas a través del cine. Por ello, sus títulos destacan el protagonismo de la gente humilde y sencilla que lucha por sobrevivir, y apuestan por un tono amable e incluso optimista ante la adversidad, pero siempre emotivo. Estos planteamientos posibilitaron que sus historias conectaran con los espectadores de este periodo.

A este respecto, Juan Nadie es un filme que plantea una problemática social determinada, que resulta injusta y cruel para la población, para después ir mostrando que la solución a la misma pasa por la aplicación de las políticas del New Deal, que, en realidad, entroncan con el espíritu de lucha de la población americana. Se trata de una película triunfante por una parte, pero derrotista por otra, que no duda en mostrar la abrupta inversión del idealismo de las masas en desilusión, sobre todo al tratarse de un idealis- 
mo manipulado y orquestado desde el poder. En este sentido, aborda el peligro que conlleva el populismo más demagógico, pues refleja cómo un ciudadano anónimo puede convertirse en la marioneta de un poder corrupto que solo desea controlar a quienes se identifican con él. Además de propagar y defender el New Deal-como sucedía en otros títulos de la época y del director-, el filme pretende educar a la ciudadanía en base al mismo, indicando cuál es el camino a seguir, especialmente al acentuar el peligro que supone el fascismo como alternativa a la democracia. De esta manera, "Capra propone como solución a estas tentaciones totalitarias, la recuperación de los valores que se encarnan en el hombre común estadounidense" (Girona 2008, 278). Por este motivo, no realiza una crítica del sistema político y social norteamericano, sino de ciertos medios de comunicación y algunos políticos que manipulan a la sociedad, de manera que "the injustices that are described and represented are particular to specific local government administrators and media outlet owners" (Siomopoulos 2012, 37).

Esta dicotomía ideológica se transmitió a través de unos personajes masculinos y femeninos que se erigieron en patrones y modelos para la sociedad americana que intentaba superar las secuelas de la Depresión y que tenía en el star system de Hollywood su universo mitológico. En primer lugar, la protagonista representa el espíritu independiente que anhelaban muchas mujeres americanas de la época, así como el éxito profesional por encima del amoroso, y en su vehemente denuncia contra la injusticia social, la corrupción y el paro, apuesta por el New Deal como fórmula para construir una sociedad más justa, honrada y productiva. La apuesta por Barbara Stanwyck para interpretar a Ann resultó muy acertada porque la actriz ya había dado vida en el cine a otras jóvenes trabajadoras y luchadoras, y así los espectadores pudieron asociar mejor la naturaleza del personaje con la personalidad de la estrella. En segundo lugar, junto a esta mujer moderna aparece John, un hombre sencillo, íntegro y honesto que refleja a los perjudicados por la Depresión y que se convierte en el líder de los más vulnerables gracias a un mensaje esperanzador que procede de los profundos ideales del New Deal. Además, es un representante del americanismo por su trayectoria como jugador de beisbol. Gary Cooper otorgó una gran credibilidad al personaje tanto por su interpretación como por su experiencia en el celuloide como héroe americano idealista. Estos patrones manifiestan que el star system estaba al servicio de los valores propagandísticos del gobierno. Por último, Norton personifica el prototipo de magnate sin escrúpulos que solo actúa movido por sus intereses, a pesar de que estos puedan suponer una amenaza para la convivencia pacífica de la sociedad.

En este sentido, la condición clásica del héroe -en lo que respecta a valores como el honor y la bondad-, se enfocaba a cómo los espectadores debían ser y actuar, mientras que la actitud resolutiva de la heroína para enfrentarse a la adversidad se dirigía a las espectadoras. John y Ann encarnaron un prototipo masculino y otro femenino, respectivamente, y exhibieron una profunda conciencia social. Así, en el universo del cineasta, los protagonistas defienden unos valores idealistas, mientras que los antagonistas ambicionan los materialistas, y esta oposición -que propiciaba la aceptación y el rechazo del público-, coincidía con las estrictas normas del Código Hays desde 1933. Además, revelaba la presencia de la moral cristiana en Hollywood, pues los sujetos que actuaban de forma positiva eran recompensados y los que procedían de manera negativa eran castigados. El inicio de la Segunda Guerra Mundial también determina la caracterización de los personajes, ubicando a John y a Ann en la órbita de los aliados y a Norton en la fascista, como se aprecia cuando se dirigen a las masas. Capra realiza una idílica defensa de Estados Unidos que se plasma en la pareja protagonista, así que, a pesar de que en el filme el mal está tan desarrollado como el bien, el happy end se presenta como la única solución posible para enviar a la ciudadanía estadounidense un mensaje positivo y de fraternidad ante la corrupción mediática y política que amenazan el país. En definitiva, la propaganda en el cine hollywoodiense realizado durante el New Deal apuesta por un modelo de sociedad democrática, como demuestran los protagonistas de Juan Nadie. 


\section{REFERENCIAS}

Aguilera, Christian, y Sergi Grau. Barbara Stanwyck. Una gran señora de Hollywood. Madrid: T\&B Editores, 2015.

Antuñano San Luis, Jaume. "Hollywood y la configuración de la historia oficial: la Segunda Guerra Mundial según la serie documental Why We Fight (Frank Capra, 1945-1945)." L'Atalante. Revista de Estudios Cinematográficos 22 (2016): 33-44. http://www.revistaatalante.com/index. php?journal=atalante\&pa ge $=$ article\&op=view\&path \%5B\%5D=350\&p ath $\% 5 B \% 5 D=337$

Bordwell, David, Staiger, Janet, y Kristin Thompson. El cine clásico de Hollywood. Estilo cinematográfico y modo de producción hasta 1960. Barcelona: Ediciones Paidós, 1997.

Capra, Frank. Frank Capra: el nombre delante del título. Autobiografía. Madrid: T\&B Editores, 2000.

Capra, Frank, Riskin, Robert (productores), y Frank Capra (director). Juan Nadie [cinta cinematográfica]. Estados Unidos: Frank Capra Productions y Warner Bros Studio, 1941.

Casetti, Francesco, y Federico Di Chio. Cómo analizar un film. Barcelona: Ediciones Paidós, 2007.

Chatman, Seymour. Historia y discurso. La estructura narrativa en la novela y en el cine. Madrid: Taurus Humanidades, 1990.

Coursodon, Jean-Pierre. "La evolución de los géneros." In Historia General del Cine. Volumen VIII. Estados Unidos (1932-1955), editado por Esteve Riambau y Casimiro Torreiro, 225-307. Madrid: Ediciones Cátedra, 1996.

Echart, Pablo La comedia romántica del Hollywood de los años 30 y 40. Madrid: Ediciones Cátedra, 2005.

Freixas, Ramón, y Joan Bassa. "Hollywood: censura y libertad. Pre-Code 1930-1934, un periodo excepcional." Dirigido 428 (2012): 55-73.

Gallagher, Tag. "Directores de Hollywood". In Historia General del Cine. Volumen VIII. Estados Unidos (1932-1955), editado por Esteve Riambau y Casimiro Torreiro, 311-403. Madrid: Ediciones Cátedra, 1996.
García de Lucas, Virginia, Rodríguez Merchán, Eduardo, y Javier Sales Heredia. Cine entre líneas. Periodistas en la pantalla. Valladolid: Semana Internacional de Cine de Valladolid, 2006.

Girona, Ramón. “Estados Unidos en Guerra. Why We Fight de Frank Capra. La historia al servicio de la causa aliada." Archivos de la Filmoteca 55 (2007): 41-57. http://www.archivosdelafilmoteca.com/index.php/archivos/article/ view/229/231

Girona, Ramón. Frank Capra. Madrid: Ediciones Cátedra, 2008.

Guiralt Gomar, Carmen. "Joan Crawford: creación de la working girl y continuidad de la 'fórmula Crawford'." Ars Longa 17 (2008): 135-147.

Guarinos, Virginia. "Mujeres en proyección. La mujer en el cine. Teoría fílmica Feminista." In La mirada de las mujeres en la sociedad de la información, coordinado por Felicidad Loscertales y Trinidad Núñez. Madrid: Siranda Editorial, 2007.

Gubern, Román. Historia del cine. Barcelona: Editorial Anagrama, 2016.

Huici, Adrián. Teoría e historia de la propaganda. Madrid: Editorial Síntesis, 2017.

Lanuza Avello, Ana. "La madre en el cine del New Deal". Tesis Doctoral, Universidad CEU San Pablo, Madrid, 2010.

Laviana, Juan Carlos. Los chicos de la prensa. Madrid: Nickel Odeón Dos, 1996.

Machacuay, Alejandro. "¡Qué bello es vivir! (Frank Capra) 60 años después." Revista de Comunicación 6 (2007): 123-130. http://revistadecomunicacion.com/pdf/2007/Art123130.pdf

Mainer, Carmen. "El cine norteamericano durante la Gran Depresión (1929-1939)." Fotocinema. Revista Científica de Cine y Fotografía 6 (2013): 171-200. https://doi.org/10.24310/ Fotocinema.2013.v0i6.5914

McBride, Joseph. Frank Capra: The Castastrophe of Success. Jackson: University Press of Mississippi, 2011. https://doi.org/10.14325/mississippi/9781604738384.001.0001 
Mera Fernández, Montse. "Periodistas de película. La imagen de la profesión periodística a través del cine." Estudios sobre el mensaje periodístico 14 (2008): 505-525. http://revistas.ucm.es/index.php/ESMP/article/view/ESMP0808110505A/11987

Meyers, Jeffrey. Gary Cooper. El héroe americano. Madrid: T\&B Editores, 2011.

Muscio, Giuliana. "El New Deal." In Historia General del Cine. Volumen VIII. Estados Unidos (1932-1955), editado por Esteve Riambau y Casimiro Torreiro, 15-41. Madrid: Ediciones Cátedra, 1996.

Pavés, Gonzalo, y M. Edward Dmytryk. "80 años alrededor de una mirada." L'Atalante. Revista de Estudios Cinematográficos 27 (2019): 131151. http://www.revistaatalante.com/index.ph p?journal $=$ atalante\&page $=$ article $\& o p=v i e w \& p$ ath $\%$ 5B\% 5D $=733$ \&path \% 5B\% 5D =518

Pelaz López, José-Vidal. "La crisis de la democracia en América. Caballero sin espada (Frank Capra, 1939)." En La historia a través del cine: Estados Unidos, una mirada a su imaginario colectivo, editado por Coro Rubio Pobes, 83110. Bilbao: Universidad del País Vasco. Servicio de Publicaciones, 2010.

Pérez Rufí, José Patricio. Desmontando al protagonista del cine clásico. Madrid: Quiasmo Editorial, 2009.

Peris Cancio, José Alfredo, y José Sanmartín Esplugues. "La locura del dólar. El relato de la vida económica en American Madness (1932), de Frank Capra." SCIO. Revista de Filosofía 13 (2017): 121-154. https://online.ucv.es/revistascio/files/2017/12/A5-peris.pdf

Prats, Lluís. Cine para educar. Guía de más de 200 películas con valores. Barcelona: Belaqva de Ediciones y Publicaciones, 2005.

Sánchez-Escalonilla, Antonio. "Indiewood y las narrativas de la crisis. La vigencia del arquetipo doméstico del New Deal." L'Atalante. Revista de estudios cinematográficos 16 (2013): 7078. http://www.revistaatalante.com/index.ph p?.journal $=$ atalante $\&$ page $=$ article $\& o p=$ view $\&$ path $\% 5 B \% 5 D=32$

Sánchez Noriega, José Luis. Historia del cine. Teorías, estéticas, géneros. Madrid: Alianza Editorial, 2018.

Siomopoulos, Anna. Hollywood Melodrama and the New Deal. Public Daydreams. New York: Routledge, 2012. https://doi. org/10.4324/9780203127643

Smedley, Nick. A Divided World: Hollywood Cinema and Emigre Directors in the Era of Roosevelt and Hitler, 1933-1948. Bristol: Intellect Books, 2011.

Torreiro, Casimiro. "La Guerra Mundial: Hollywood entre dos frentes." In Historia General del Cine. Volumen VIII. Estados Unidos (1932-1955), editado por Esteve Riambau y Casimiro Torreiro, 43-79. Madrid: Ediciones Cátedra, 1996.

Willis, Donald C. Frank Capra. Madrid: Ediciones JC, 1988. 